\title{
Improving Student Learning Outcomes with Power Point Media Through The Zoom Application on Learning Various Occupational Themes
}

\author{
Triana Kusumawati \\ SD Negeri 02 Tegalsari \\ trianakusumawati156@gmail.com
}

\section{Article History}

accepted $14 / 11 / 2020$

approved $21 / 11 / 2020$

published 26/11/2020

\begin{abstract}
The purpose of this study was to improve student learning outcomes in learning the various themes of class 4 work. This research was a classroom action research (CAR) which was carried out in three cycles, each cycle consisting of planning, implementation, observation, and reflection stages. The subjects of this study were the fourth grade students of SD Negeri 02 Tegalsari in the 2020/2021 school year, totaling 14 students. Data collection techniques using tests. Data analysis includes data reduction, data presentation, and drawing conclusions. Research shows that the application of power point media can improve student learning outcomes on the subject matter of various jobs in class IV SD Negeri 02 Tegalsari in the 2020/2021 school year as evidenced by the percentage of completeness of learning outcomes in cycle I of $71 \%$, cycle II of $86 \%$, and become $93 \%$ in cycle III.
\end{abstract}

Keywords: Power point media, zoom applications, learning outcomes

\section{Abstrak}

Tujuan penelitian ini adalah meningkatkan hasil belajar siswa pada pembelajaran tema berbagai pekerjaan kelas 4 . Penelitian ini merupakan penelitian tindakan kelas (PTK) yang dilaksanakan dalam tiga siklus, setiap siklus terdiri dari tahap perencanaan, pelaksanaan, observasi, dan refleksi. Subjek penelitian ini adalah peserta didik kelas IV SD Negeri 02 Tegalsari tahun pelajaran 2020/2021 yang berjumlah 14 peserta didik. Tekni pengumpulan data menggunakan tes. Analisis data meliputi reduksi data, penyajian data, dan penarikan kesimpulan. Penelitian menunjukkan bahwa penerapan media power point dapat meningkatkan hasil belajar siswa pada materi tema berbagai pekerjaan di kelas IV SD Negeri 02 Tegalsari tahun pelajaran 2020/2021yang dibuktikan dengan persentase ketuntasan hasil belajar pada siklus I sebesar $71 \%$, siklus II sebesar $86 \%$, dan menjadi $93 \%$ pada siklus III.

Kata kunci: Media power point, aplikasi zoom, hasil belajar

Social, Humanities, and Education Studies (SHEs): Conference Series https://jurnal.uns.ac.id/shes 


\section{PENDAHULUAN}

Pandemi Covid-19 yang melanda dunia sangat mempengaruhi kehidupan manusia. Tidak hanya mempengaruhi dalam bidang kesehatan, tetapi juga bidang ekonomi dan pendidikan. Berdasarkan Surat Edaran Menteri Pendidikan dan Kebudayaan Nomor 4 Tahun 2020 ini mengatur tentang Pelaksanaan Kebijakan Pendidikan dalam Masa Darurat Penyebaran Covid-19 (https://www.kemdikbud.go.id). Surat edaran ini mengharuskan peserta didik untuk mengikuti kegiatan pembelajaran jarak jauh (PJJ). Oleh karena itu, guru dan peserta didik dituntut untuk menguasai berbagai aplikasi pembelajaran online. Keuntungan pembelajaran dengan teknologi dapat menciptakan iklim belajar yang efektif bagi siswa yang lamban dalam pembelajaran, merangsang siswa dalam mengerjakan latihan dan dapat menyesuaikan kecepatan kecepatan belajar dapat sesuai dengan kemampuan siswa (Made Wena, 2011).

Namun, penggunaan media pembelajaran daring yang kurang menarik merupakan salah satu faktor penyebab kurang maksimalnya hasil belajar menemukan kosakata dan makna kosakata yang berkaitan kehidupan sosial di kelas IV SDN 02 Tegalsari. Guru melakukan kegiatan pembelajaran berbasis daring dalam bentuk yang kurang menarik minat peserta didik, sehingga banyak peserta didik yang tidak aktif mengikuti pembelajaran dan mempengaruhi terhadap hasil belajarnya.

Berdasarkan hasil pengamatan hasil belajar siswa kelas IV SDN 02 Tegalsari pada mata pelajaran PPKn materi tema berbagai pekerjaan kelas 4 yaitu dari 27 siswa, terdapat 20 siswa mendapat nilai $\geq 70$, sedangkan 7 siswa mendapat nilai $\leq 70$. Dapat disimpulkan bahwa hanya 65\% siswa lulus KKM dan 35\% tidak lulus KKM .

Ada beberapa penyebab rendahnya hasil belajar

materi menemukan kosakata dan makna kosakata berkaitan kehidupan sosial, diantaranya : (1) Guru masih menggunakan media pembelajaran daring yang kurang tepat; (2) Guru tidak menguasai media pembelajaran daring; (3) Siswa kurang aktif dalam pembelajaran daring.

Penerapan E-Learningsaat ini sudah mulai berkembang di dunia pendidikan baik di kota besar maupun di kota kecil sebagaialternatifmodel merdeka belajar di masa adaptasi Kebiasaan Baru (New Normal).

Hal ini disebabkan oleh beberapa keunggulan dan kelebihan yang dimiliki teknologi informatika yang saat ini telah berkembang demikian pesat, sehingga memungkinkan penggunanya dapat bekerja secara cepat, akurat, dan memiliki jaringan yang sangat luas. Contoh nyata dari pemanfaatan teknologi ini adalah dengan pembuatan media pembelajaran yang memanfaatkan program aplikasi Microsoft Power Point. Program ini memiliki kemampuan yang sangat baik dalam menyajikan sebuah materi presentasi dan sudah banyak digunakan dalam dunia pendidikan.

Pada observasi awal sebelum memanfaatkan media pembelajaranberbasis power point melalui aplikasi zoom hasil belajar siswa masih rendah pada muatan PPKn Tema 4 Berbagai Pekerjaan Subtema 1pada kelas 4 Semester 1 Tahun Pelajaran 2020/2021 di SDN 02 Tegalsari. Perlunya inovasi dalam pembelajaran ini tentunya diharapkan dapat meningkatkan kualitas pembelajaran siswa khususnya di masa adaptasi kebiasaan baru (New Normal) pada siswa kelas 4 Semester 1 Tahun Pelajaran 2020/2021 Di SDN 02 Tegalsari Kecamatan Ampelgading, Kabupaten Pemalang, Jawa Tengah.

Berdasarkan hasil observasi aktivitas siswa yang dilakukan di kelas 4 Semester 1 Tahun Pelajaran 2020/2021 Di SDN 02 Tegalsari, pada saat pembelajaran berlangsung, yaitu siswa kurang berperan aktif. Pembelajaran di dominasi oleh guru. Sebagian siswa hanya mendengarkan dan mencatat penjelasan dari guru.

Berdasarkan latar belakang yang telah diuraikan di atas, dengan mempertimbangkan solusi, peneliti menganggap bahwa penerapan Cooperative Learning Tipe Student Team Achievement Division (STAD)ke dalam pembelajaran 
sangatlah penting, sehingga perlu dilakukan penerapan model tersebut ke dalam pembelajaran melalui penelitian yang berjudul "Peningkata hasil belajar dengan media power point melalui aplikasi zoom pada sub tema jenis jenis pekerjaan kelas 4 SDN 02 Tegalsari

\section{METODE}

Penelitian ini merupakan penelitian tindakan kelas (PTK) kolaboratif yang dilaksanakan dalam tiga siklus, setiap siklus terdiri dari tahap perencanaan, pelaksanaan, observasi, dan refleksi. Subjek penelitian ini adalah peserta didik kelas IV SD Negeri 02 Tegalsari tahun pelajaran 2020/2021 yang berjumlah 14 siswa.

Data yang dianalisis berupa data kualitatif yaitu hasil belajar Bahasa Indonesia peserta didik. Teknik pengumpulan data menggunakan tes. Uji validitas data menggunakan triangulasi teknik dan triangulasi sumber. Analisis data meliputi reduksi data, penyajian data, dan penarikan kesimpulan.

\section{HASIL DAN PEMBAHASAN}

Hasil penelitian menunjukkan peningkatan hasil belajar pada materi tema berbagai pekerjaan kelas 4 . Terlihat pada tabel berikut.

Tabel 1. Peningkatan Hasil Belajar

\begin{tabular}{ccccccc}
\hline \multirow{2}{*}{ Nilai } & \multicolumn{2}{c}{ Siklus I } & \multicolumn{2}{c}{ Siklus II } & \multicolumn{2}{c}{ Siklus III } \\
& $\mathrm{f}$ & $\%$ & $\mathrm{f}$ & $\%$ & $\mathrm{f}$ & $\%$ \\
\hline 100 & 1 & 7 & 2 & 14 & 3 & 22 \\
80 & 9 & 64 & 10 & 71 & 10 & 71 \\
60 & 4 & 29 & 2 & 15 & 1 & 7 \\
40 & 0 & 0 & 0 & 0 & 0 & 0 \\
20 & 0 & 0 & 0 & 0 & 0 & 0 \\
Jumlah & 1.040 & & 1.120 & & 1.160 & \\
Rata-rata & 74,29 & & 80 & & 82,86 & \\
Tuntas & 10 & $71 \%$ & 12 & $86 \%$ & 13 & $93 \%$ \\
\hline
\end{tabular}

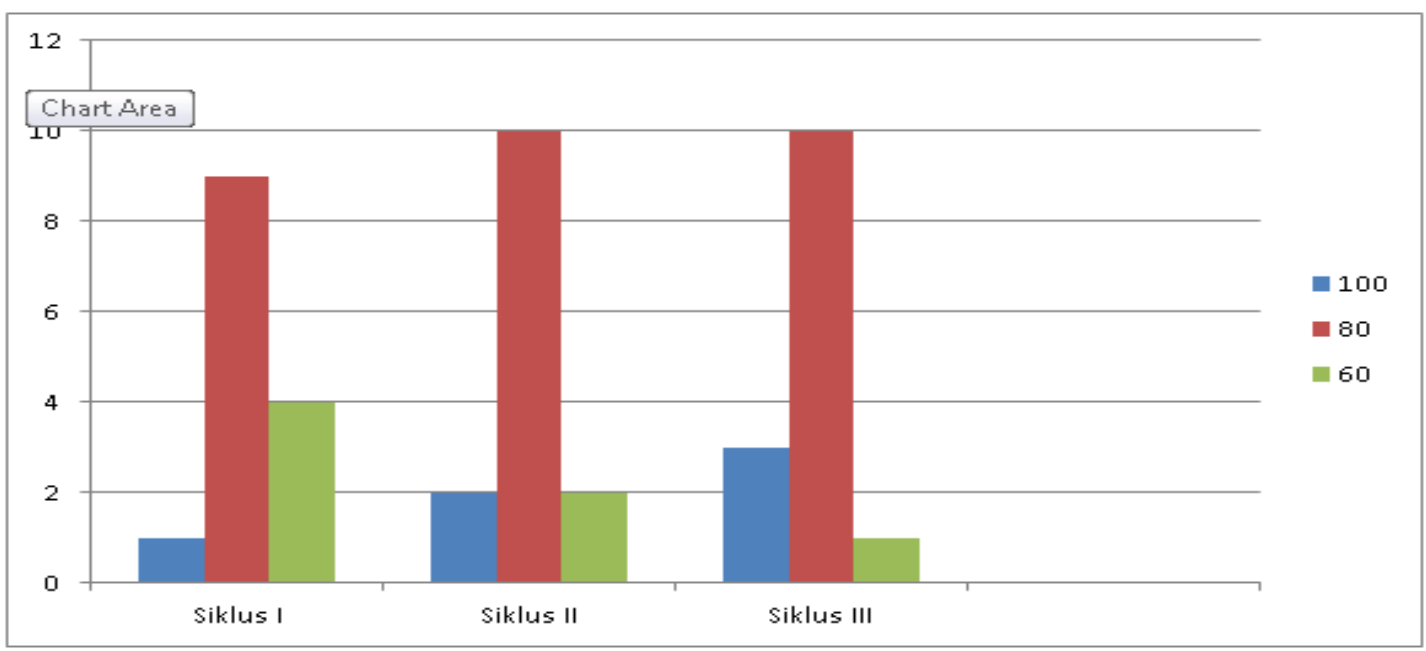

Gambar 1. Hasil Belajar 
Peningkatan hasil belajar pada materi tema berbagai pekerjaan diukur dengan menggunakan teknik tes hasil belajar dengan instrumen lembar soal evaluasi. Teknik pengumpulan data hasil belajar peserta didik diterapkan di setiap pertemuan setelah dilakukan kegiatan pembelajaran. Aspek yang diukur yaitu aspek kognitif atau pengetahuan yang terdiri dari menganalisis (C4) dan menemukan (C4) yang diukur berdasarkan hasil evaluasi setelah mengikuti pembelajaran dengan menggunakan media audio visual melalui powerpoint pada materi tema berbagai pekerjaan.

Penggunaan media audio visual melalui powerpoint pada materi tema berbagai pekerjaan dapat meningkatkan hasil belajar peserta didik di kelas IV SD Negeri 02 Tegalsari. Pada hasil penilaian sebelumnya persentase ketuntasan belajar hanya $65 \%$. Setelah dilakukan tindakan, persentase ketuntasan belajar meningkat menjadi $71 \%$. Pada siklus II terjadi peningkatan kembali yang mencapai $86 \%$. Peningkatan kembali terjadi pada siklus III yaitu sebesar 93\% dengan KKM 70 sehingga pelaksanaan tindakan dapat dihentikan.

Berdasarkan tabel hasil belajar peserta didik terhadap penggunaan media audio visual melalui power point dapat dilihat bahwasanya peserta didik sangat tertarik untuk mengikuti pembelajaran materi tema berbagai pekerjaan dikelas 4. (Luqman et al., 2017) menyatakan bahwa pembelajaran yang menyenangkan, menarik minat dan tidak membosankan peserta didik, salah satu awal agar pembelajaran menjadi bermakna yang pada akhirnya dapat meningkatkan hasil belajar peserta didik.

\section{SIMPULAN}

Penggunaan media audio visual mealui power point dalam pembelajaran tema berbagai pekerjaan sangat memotivasi siswa dalam belajar. Media audio visual mealui power point dapat menarik minat dan keaktifan siswa dalam kegiatan pembelajaran. Hal ini sangat berpengaruh terhadap peningkatan hasil belajar siswa yang dengan ketuntasan hasil belajar peserta didik pada siklus I sebesar $71 \%$, meningkat menjadi $86 \%$ pada siklus II, dan lebih meningkat pada siklus III menjadi 93\%.

Berdasarkan hasil penelitian tindakan kelas tersebut, guru dapat melibatkan siswa dalam pemanfaatan kemajuan teknologi dengan bantuan media audio visual melalui poerpoint dengan aplikasi zoom agar siswa lebih menguasai materi pembelajaran, sehingga hasil belajarnya meningkat. Sekolah hendaknya memotivasi guru untuk terus berusaha memanfaatkan teknologi dalam kegiatan pembelajaran yang berdampak pada peningkatan hasil belajar siswa

\section{DAFTAR PUSTAKA}

Depdikbud. 1995. Petunjuk Pelaksanaan Kegiatan Belajar Mengajar, Jakarta : Dekdasmen

Dimyati. 1994. Belajar dan Pembelajaran. Jakarta : Dirjen Dikti

Ebru, D. S. (2017). Ask Response Play Learns : Student's View On Gamification Based Interactive Response System. Journal of Education Ans Instructional Studies Un The World, Vol 7, Issue: 3, ISSN: 2146-7463.

Ilmiyah, N. H. \& Sumbawati, M. S. (2019). Pengaruh Media Kahoot dan Motivasi Belajar Terhadap Hasil Belajar Siswa. JIEET: Volume 03 Nomor 01, 2019

Luqman, M., Hakim, I., Saad, M., Teknologi, U., Zulfadhli, A., Universiti, N., ... Saad, Made Wena. (2011). Strategi Pembelajaran Inovatif Kontemporer. Bumi Aksara.

SE Mendikbud: Pelaksanaan Kebijakan Pendidikan dalam Masa Darurat Penyebaran Covid-19. (2020). https://ww.kemdikbud.go.id 